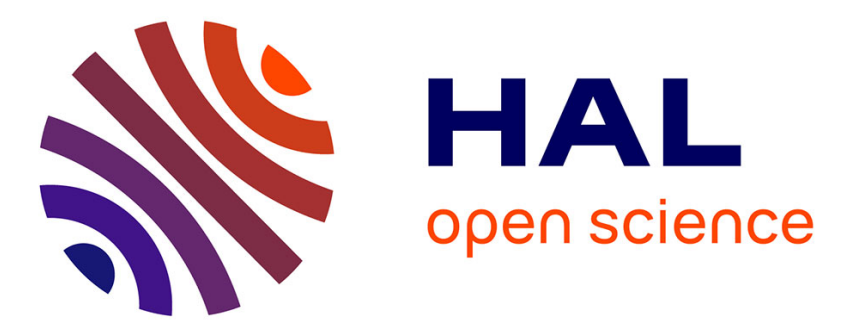

\title{
Indirect Nanoplasmonic Sensing to Probe with a High Sensitivity the Interaction of Water Vapor with Soot Aerosols
}

Benjamin Demirdjian, Frederic Bedu, Alain Ranguis, Igor Ozerov, Artak Karapetyan, Claude R. Henry

\section{To cite this version:}

Benjamin Demirdjian, Frederic Bedu, Alain Ranguis, Igor Ozerov, Artak Karapetyan, et al.. Indirect Nanoplasmonic Sensing to Probe with a High Sensitivity the Interaction of Water Vapor with Soot Aerosols. Journal of Physical Chemistry Letters, 2015, 6 (20), pp.4148-4152. 10.1021/acs.jpclett.5b01630 . hal-01215596

\section{HAL Id: hal-01215596 \\ https://hal.science/hal-01215596}

Submitted on 19 May 2021

HAL is a multi-disciplinary open access archive for the deposit and dissemination of scientific research documents, whether they are published or not. The documents may come from teaching and research institutions in France or abroad, or from public or private research centers.
L'archive ouverte pluridisciplinaire HAL, est destinée au dépôt et à la diffusion de documents scientifiques de niveau recherche, publiés ou non, émanant des établissements d'enseignement et de recherche français ou étrangers, des laboratoires publics ou privés. 
Indirect Nanoplasmonic Sensing to Probe with a High Sensitivity the Interaction of Water Vapor with Soot Aerosols.

Benjamin Demirdjian*, Frederic Bedu, Alain Ranguis, Igor Ozerov, Artak Karapetyan and Claude R. Henry

Aix-Marseille Université, CNRS, CINaM UMR 7325, 13288 Marseille, France

*Corresponding author:

B. Demirdjian, Aix-Marseille University, CNRS, CINaM UMR 7325, 13288 Marseille, France mobile: +33 (0)6 6036 2818, fax: +33 (0)4 9141 8916, e-mail: demirdjian@cinam.univ-mrs.fr 


\section{ABSTRACT}

We demonstrate in this work that the indirect nanoplasmonic sensing lets us to follow the adsorption/desorption of water molecules on soot particles that are a major contributor of the global warming. Increasing the relative humidity of the surrounding medium we measure a shift in wavelength of the localized surface plasmon resonance response of gold nanodisks on which soot particles are deposited. We show a singular and reversible blue-shift with hydrophilic aircraft soot particles interpreted from a basic model as a reversible morphological change of the soot aggregates. This new method is highly sensitive and interesting to follow the change of optical properties of aerosols during their aging in the atmosphere where they can adsorb and react with different gas molecules.

\section{TOC GRAPHICS}

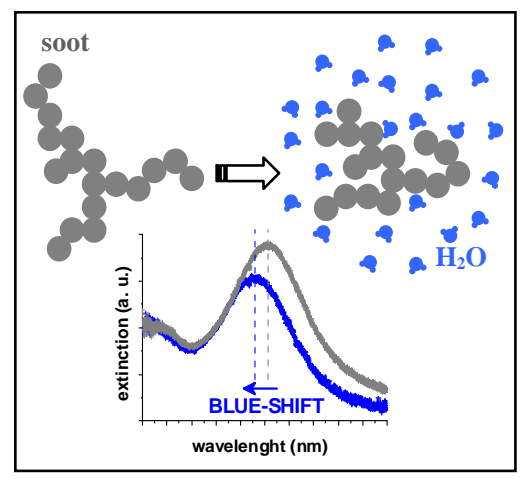

KEYWORDS: Nanoplasmonic, interaction water/soot, aerosols optical properties, morphological change, UV-Vis spectroscopy. 
Advancements in nanotechnologies allow the interaction between different scientific fields particularly in the development of chemical ${ }^{1,2}$ and biological nanosensors ${ }^{3,4}$ based on the extraordinary optical properties of noble metal nanoparticles. Nanosensors based on surface plasmon resonance (SPR) and localized surface plasmon resonance (LSPR) are sensitive to small local changes in refractive index at the surface of metal nanoparticles during the adsorption/desorption of molecules. These changes induce a shift in the wavelength of the LSPR response. ${ }^{2,5}$ Variations of the reflectivity as a function of the incidence angle for SPR and the LSPR peak extinction are linked to the same physical phenomena: the collective oscillation of electrons in the metal. The minimum of reflection corresponds to a maximum of absorption. The response of LSPR and SPR nanosensors follows a simple model described by the group of Campbell ${ }^{6}$ :

$$
\Delta \lambda=m\left(n_{2}-n_{1}\right)\left[1-\exp \left(\frac{-2 d}{l_{d}}\right)\right]
$$

where $\Delta \lambda$ is the wavelength shift, $m$ is the sensitivity of the refractive index (RI), $n_{2}$ and $n_{1}$ are the RIs of different surrounding media, $d$ is the effective thickness of the adsorbed layer and $l_{d}$ is the characteristic decay length of the evanescent electromagnetic field. This decay length depends on the size, shape and composition of the nanoparticles. For SPR sensors this length $l_{d}$ is about 200$300 \mathrm{~nm}^{7}$ and their refractive index sensitivity is $m=2 \times 10^{6} \mathrm{~nm} /$ RIU (Refractive Index Units). ${ }^{6}$ For LSPR sensors the refractive index sensitivity is lower $\left(m \approx 2 \times 10^{2} \mathrm{~nm} / \mathrm{RIU}\right)$, this is compensated by a smaller value of the decay length $l_{d}$ of 5-40 nm..$^{2,7,8,9,10,11}$ LSPR sensors do not require temperature control with respect to the SPR sensors that have a high refractive index sensitivity ( $\rightarrow$ strong dependence of the ambient temperature). In addition there are neither particular angular nor polarization conditions for LSPR sensors. Moreover, they do not require to use a prism or waveguide. Measurements can be performed with a simple UV-visible spectrometer in the transmission mode. 
In this work our aim is to study the reactivity of water with soot nanoparticles deposited on gold nanodisks acting individually as nanodetectors. Soot aerosols affect the Earth's energy balance by absorbing solar radiation, influence cloud processes, and alter the melting of snow and ice cover. ${ }^{12-}$ ${ }^{14}$ Because the black carbon in soot aerosols dominates the absorption of visible solar radiation, soot aerosols are the second most important contributor of global warming after carbon dioxide in terms of direct forcing in the present-day atmosphere. ${ }^{15}$ Moreover, the comparison between field and remote sensing observations with many climate simulation models indicates that the atmospheric absorption attributable to soot aerosols is too low in many climate models studies; these differences have not been extensively examined and they are not well-understood. ${ }^{16}$ This significant undervaluation is linked to the lack of knowledge about the optical properties of soot aerosols that depend strongly on their morphology. ${ }^{17,18}$ The hygroscopicity of soot aerosols critically influences also their optical properties. ${ }^{19-21}$ Taking into account the lack of reliable information on the effect of atmospheric water on the optical properties of soot aerosols and the critical importance of aerosols during radiative forcing assessments, this study aims to follow the interaction of water vapor with soot particles using a LSPR sensor.

To study the system water/soot/Au nanodisks it is necessary to deposit an insulating layer $\left(\mathrm{SiO}_{2}\right)$ on gold nanodisks. Indeed Larsson et al. ${ }^{10}$ have shown that this layer protects and increases the stability of the detection nanostructure (gold nanodisks) at high temperature and it suppresses the interaction (mainly electronic interactions) between the studied nanoparticles and the gold nanodisks. The extinction spectra corresponding to LSPR responses of bare gold nanodisks and gold nanodisks covered by the $\mathrm{SiO}_{2}$ layer are shown in figure $\mathrm{S} 1$, we clearly see a red-shift of 29 nm due to the $\mathrm{SiO}_{2}$ layer deposition.

Soot nanoparticles can react with water vapor molecules that change the dielectric properties at the surface of the soot nanoparticle and generate a displacement of the LSPR wavelength of the 
underlying gold nanodetector. This is called an indirect LSPR phenomenon (or indirect nanoplasmonic sensing: INPS).

Before any study of the reactivity of soot nanoparticles with water molecules it was necessary to measure the effect of the adsorption of $\mathrm{H}_{2} \mathrm{O}$ on the bare gold nanodisks (covered by the $\mathrm{SiO}_{2}$ layer), in order to have a blank measurement. Before the introduction of water vapor, the UHV reactor was pumped until a pressure $\mathrm{P}<10^{-4} \mathrm{~Pa}\left(10^{-6} \mathrm{mbar}\right)$. Relative humidity ( $R H$ in $\left.\%\right)$ in the UHV reactor is defined as the ratio of the water vapor partial pressure to the saturated water vapor pressure at a given temperature. Figure 1 shows the evolution of the wavelength shift $\Delta \lambda$ of the LSPR response peak maximum $v s R H$ inside the reactor at room temperature.

The shift $\Delta \lambda$ is almost linear $v s$ the relative humidity. At saturation (i.e. $R H=100 \%$ ) we measure a shift $\Delta \lambda_{\max }=2.4 \mathrm{~nm}$. From three similar experiments (table S1) we determine an average value of $<\Delta \lambda_{\max }>=2.2 \mathrm{~nm} \pm 0.2 \mathrm{~nm}$. This shift corresponds to an average thickness of the water layer of $<d>=0.67 \mathrm{~nm} \pm 0.06 \mathrm{~nm}(=2.2 \mathrm{ML} \pm 0.2 \mathrm{ML}$ of liquid water assuming $0.3 \mathrm{~nm}$ per ML). This value is smaller than the value reported by Arima et al. ${ }^{22}(d \approx 1 \mathrm{~nm})$, it can be explained by the fact that in the present study the $\mathrm{SiO}_{2}$ layer is obtained by RF magnetron sputtering and contains less $\mathrm{OH}$ active sites on the surface therefore it is less hydrophilic. 


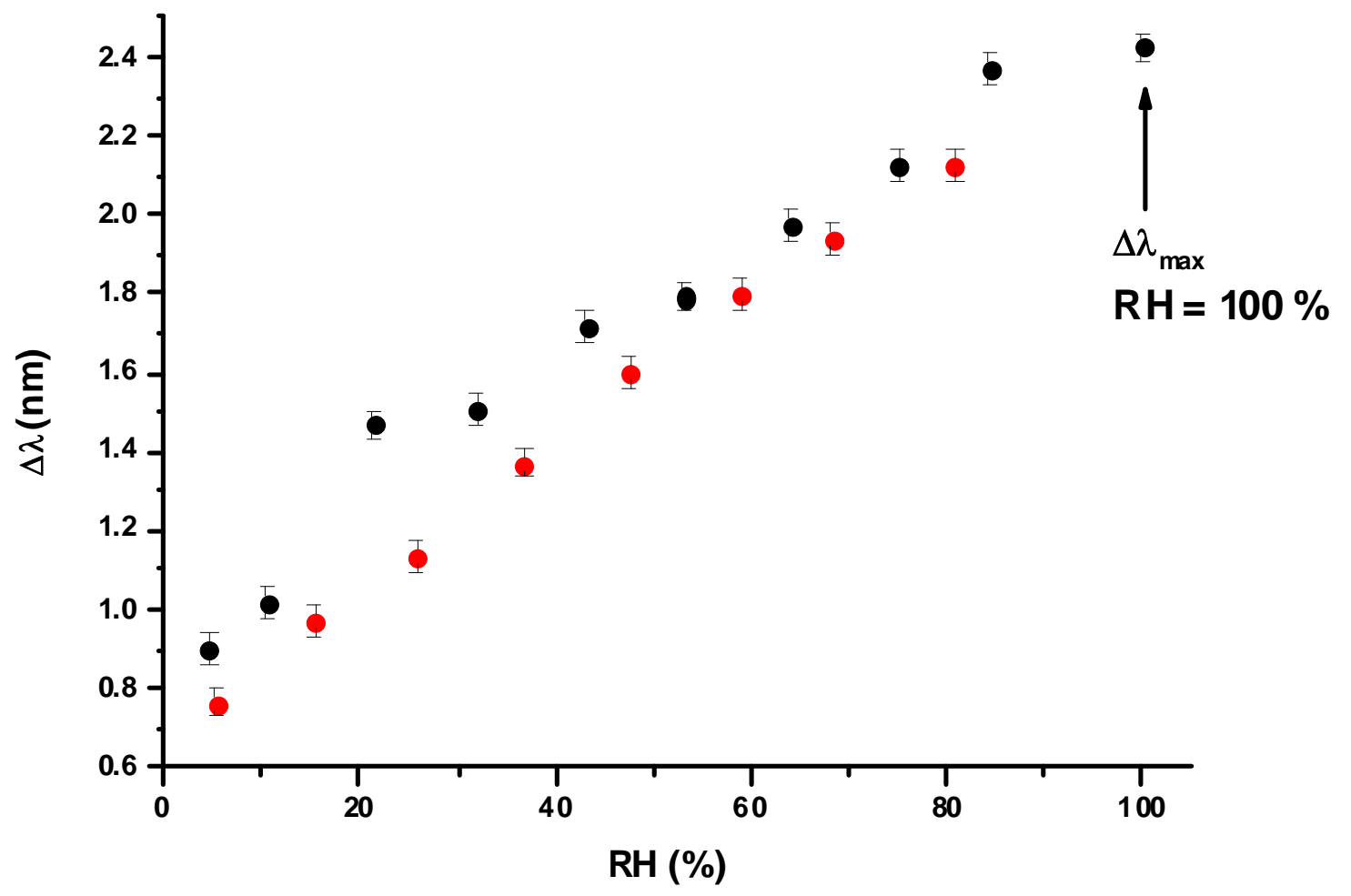

Figure 1: Evolution of the shift $\Delta \lambda$ of the LSPR response vs the relative humidity inside the reactor at room temperature during the adsorption of water vapor on the gold nanodisks covered by a $\mathrm{SiO}_{2}$ layer. Black dots are obtained during the adsorption, red dots are obtained during the desorption. Error bars are indicated.

A striking conclusion is that this technique is highly sensitive to follow the adsorption of water molecules on $\mathrm{SiO}_{2}$, indeed the accuracy of the wavelength measurement in the LSPR response is $0.04 \mathrm{~nm}$ corresponding to the detection of about 2/100 of water monolayer ! This value of $0.04 \mathrm{~nm}$ results from the fitting procedure of the extinction spectrum of fig. $\mathrm{S} 1$ (with the $\mathrm{SiO}_{2}$ layer), it corresponds to the error bar on fig. 1 .

We observe a good reversibility between the adsorption and desorption curves (figure 1), thus we expect mostly physisorption and no chemisorption of water molecules onto the $\mathrm{SiO}_{2}$ layer.

One can notice that for this calculation we assume a sensitivity of the refractive index $m=200 \mathrm{~nm} /$ RIU and a decay length of the evanescent electromagnetic field $l_{d}=40 \mathrm{~nm}$. These two values are consistent with the values given in the literature for similar gold nanodisks. ${ }^{8-11}$ Finally, the variation of the refractive index induced by the adsorbate is $n_{2}-n_{1}=n\left(\mathrm{H}_{2} \mathrm{O}_{\text {liq }}\right)-n$ (vacuum) $=1.3330-1=$ 0.3330. Indeed, we assume that water condenses onto the $\mathrm{SiO}_{2}$ surface as liquid water. 
Among the large variety of soots we have characterized in the past we have chosen a sample which is known to be hydrophilic: aircraft engine combustor (AEC) soot. This sample is heterogeneous; the main fraction is composed of hemi-spherical primary particles that are essentially amorphous, the remaining part of the sample contains a wide variety of particle shapes containing hydrophilic impurities. $^{23}$

We dilute a small amount of this AEC soot (powder) in ethanol and the solution is sonicated for 20 minutes. We make a drop deposit onto the $\mathrm{SiO}_{2}$ layer covering the gold nanodisks. The extinction spectra corresponding to LSPR responses of hydrophilic soot particles deposited on the gold nanodisks (covered by the $\mathrm{SiO}_{2}$ layer) at $\mathrm{RH}=0 \%$ and $\mathrm{RH}=67 \%\left(\Delta \lambda_{\max }\right)$ are shown in figure $\mathrm{S} 2$. From the fitting procedure of the extinction spectra (figure S2) we determine the accuracy of the wavelength measurement. We find here a higher value $(0.08 \mathrm{~nm}=$ error bar in fig.2) due to a lower $\mathrm{S} / \mathrm{N}$ ratio of the LSPR response when we deposit soot particles on the gold nanodisks $\left(+\right.$ the $\mathrm{SiO}_{2}$ layer).

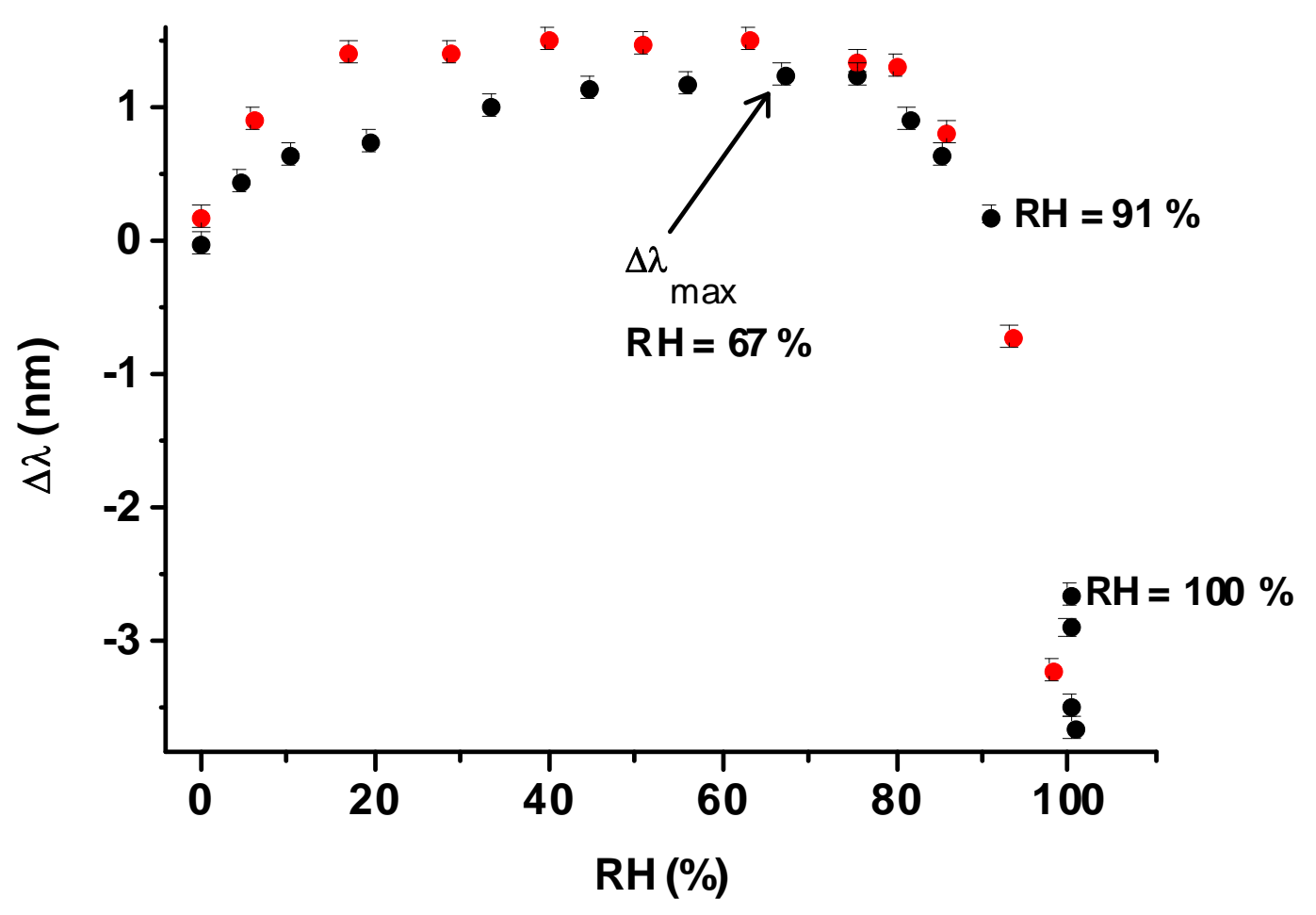

Figure 2: Evolution of the shift $\Delta \lambda$ of the LSPR response vs the relative humidity inside the reactor at room temperature during the adsorption of water vapor on soot particles deposited on gold nanodisks covered by a $\mathrm{SiO}_{2}$ layer. Black dots are obtained during the adsorption, red dots are obtained during the desorption. Error bars are indicated. 
We observe a peculiar behavior (figure 2) of the evolution of the shift $\Delta \lambda$ ( $v s$ the reactor $R H$ ) compared to that of the blank sample (figure 1). The shift gradually increases until $R H=67 \%$ $\left(\Delta \lambda_{\max }=1.3 \mathrm{~nm}\right)$ and then decreases continuously until $R H=91 \%(\Delta \lambda=0.2 \mathrm{~nm})$. At saturation conditions, i.e. $R H=100 \%$, the shift $\Delta \lambda$ drops sharply and becomes negative (blue-shift) $\Delta \lambda=-2.6$ $\mathrm{nm}$ (fig. 2). After $15 \mathrm{~min}$ at saturation the shift continues to decrease to $\Delta \lambda=-3.7 \mathrm{~nm}$ (fig. 2). The changes in the slope of $\Delta \lambda$ at $R H=67 \%$ and $R H=91 \%$ indicate that the optical properties of soot particles are modified. Finally, the adsorption and desorption curves are quasi-reversible (figure 2), we can observe a small hysteresis during the desorption phase at $R H<70 \%$. Perhaps some water molecules do not desorb completely from the soot particles.

It is impossible to explain this blue-shift with the equation (1), we should suppose that there is a modification of the optical properties of soot during water adsorption. In fact hydrophilic soot aggregates collapse into more dense structures during the increase of relative humidity up to saturation. Mikhailov et al. ${ }^{21}$ have indeed shown that at $R H=100 \%$ soot aggregates are more compact (i.e. a higher mass fractal dimension $D_{f}$ ) and have smaller gyration radius. This phenomenon is due to capillary forces applied by water molecules adsorbed on surfaces of soot primary particles. AEC soot contains a high fraction of organic carbon compounds and adsorbs a large amount of water molecules on the surface of carbon particles. ${ }^{23}$ Moreover when the mass fractal dimension $D_{f}$ of soot aggregates increases, their refractive index increases also (both the real part $\mathrm{n}$ and the imaginary part $\mathrm{k}$ ) as it has been shown by Maugendre et al. ${ }^{24}$ In order to support this explanation we make theoretical simulations.

We assume that the thickness of our soot aggregates is about $h=100 \mathrm{~nm}$ at dry conditions, this is supported by AFM measurements showing thicknesses of soot aggregates (figure S3). We make the hypothesis that during water adsorption this thickness $h$ decreases (aggregate collapsing), so we took $h=100,90$ and $80 \mathrm{~nm}$. Moreover we use realistic values of the refractive index for soot particles $^{25}:$ 1.8, 1.9 and 2.0. These 3 values correspond to different compactness of soot 
aggregates. $^{24,25}$ To validate our model (see section: computational method) we ensured that our calculations on gold thin film adsorbed on glass were in good agreement with experimental and theoretical results. ${ }^{26-29}$ Figure 3 shows the different curves of absorbance of the multilayers system soot $/ \mathrm{SiO}_{2} / \mathrm{Au} / \mathrm{glass}$ calculated for the 3 different soot aggregate thicknesses and refractive indexes. Furthermore, the simulation shows that the blue-shift of the absorbance peak depends of the soot layer thickness. The blue-shifts values are 3 and $4 \mathrm{~nm}$ for thicknesses h going from 90 to $80 \mathrm{~nm}$ and from 100 to $90 \mathrm{~nm}$, respectively. This is consistent with the blue-shift measured at saturation in fig. $2(\Delta \lambda=-3.7 \mathrm{~nm})$. So we can suppose that at water vapor saturation our soot aggregates collapse at least by $10 \mathrm{~nm}$ (i.e. $10 \%$ of their original thicknesses).

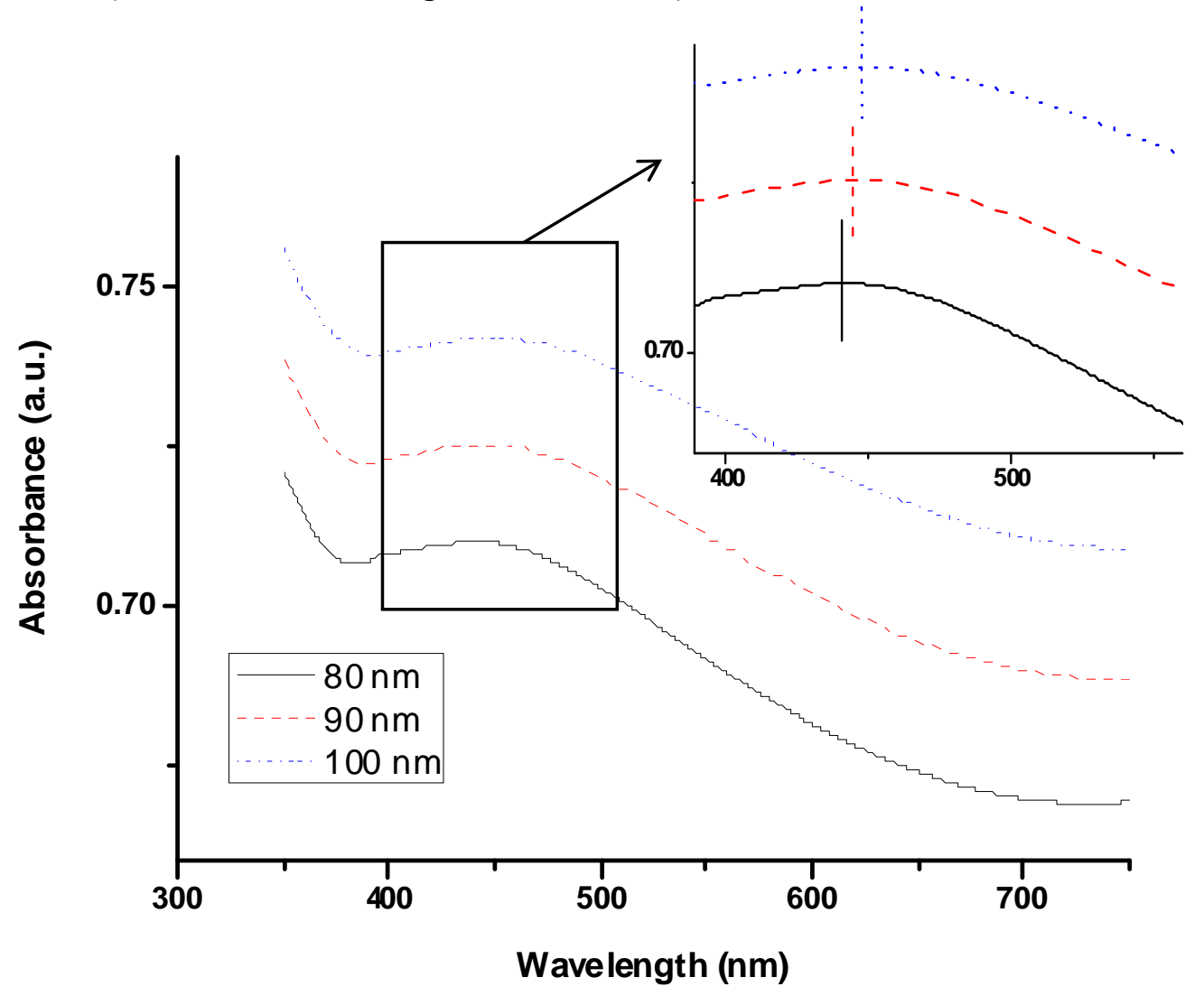

Figure 3: Absorbance of the thin multilayers system as a function of the incident wavelength: for $h_{1}$ $=80 \mathrm{~nm}, n_{1}=2:$ solid line; $h_{1}=90 \mathrm{~nm}, n_{1}=1.9:$ dash line; $h_{1}=100 \mathrm{~nm}, n_{1}=1.8:$ dot line and $k_{1}$ $=0.75$ for the three thicknesses. Maxima are indicated in the inset by vertical lines. 
Then when water molecules desorb, the soot aggregates retrieve their initial morphologies, we have shown indeed that the adsorption and desorption curves are quasi-reversible (figure 2). Moreover this phenomenon is also observed on a second adsorption/desorption cycle on the same soot sample.

For comparison we have also measured the LSPR response for hydrophobic soot particles ${ }^{23}$. As expected, they do not exhibit a behavior similar to hydrophilic soots we showed previously. We observe an increase of $\Delta \lambda$ vs $R H$ up to $2 \mathrm{~nm}$ and no blue-shift even at saturation conditions (figure 4). This result corroborates the fact that hydrophobic soot does not show any structural or morphological change going from dry to saturated conditions. ${ }^{21}$

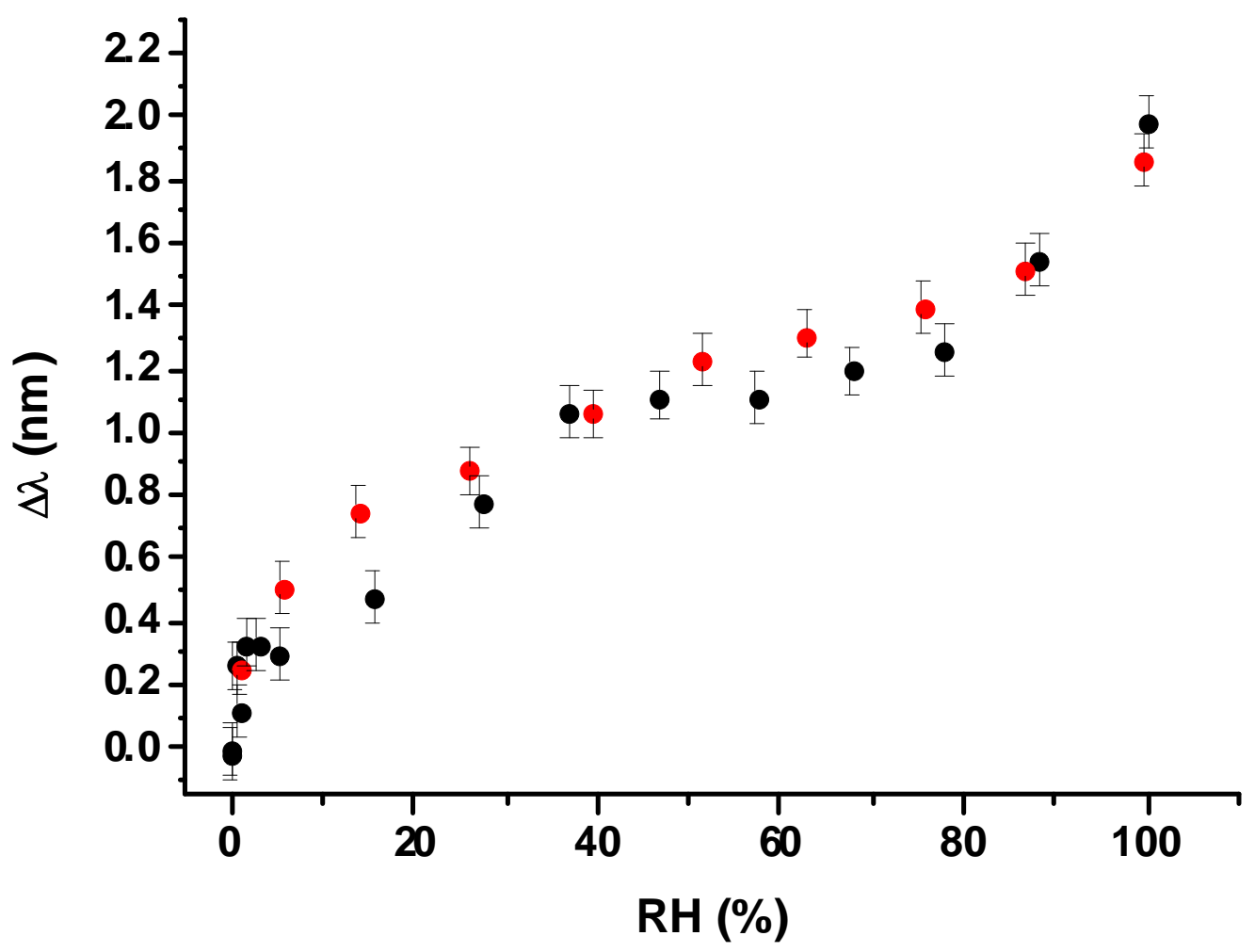

Figure 4: Evolution of the shift $\triangle \lambda$ of the LSPR response vs the relative humidity inside the reactor at room temperature during the adsorption of water vapor on hydrophobic soot particles deposited on gold nanodisks covered by a $\mathrm{SiO}_{2}$ layer. Black dots are obtained during the adsorption, red dots are obtained during the desorption. Error bars are indicated.

We have shown the evolution of the shift $\Delta \lambda$ of the LSPR response versus RH depends strongly on the soot hygroscopic character. For hydrophilic soot particles we observe a blue-shift of the LSPR response due to morphological changes that can modify the radiative properties of the soot particles 
and then affect their role on the global climate forcing. Our method can be more generally applied for the study of the reactivity and aging of fossil fuel combustion particles in the atmosphere; a major concern for the atmospheric community. ${ }^{30}$ Indeed during atmospheric processing the morphology, the chemical composition, the hygroscopicity of soot aerosols can change and modify their optical properties and the radiative forcing. ${ }^{31}$ Finally this laboratory technique is also complementary to remote sensing LIDAR observations that are useful to analyze the microphysical and optical properties of aerosols in the atmosphere. ${ }^{32}$

We have shown for the first time that the indirect nanoplasmonic sensing (INPS) allows to follow with a high sensitivity the adsorption/desorption of water molecules on soot by following the shift $\Delta \lambda$ of the LSPR response of gold nanodisks on which soot particles are deposited. With hydrophilic aircraft soot particles we have measured a singular and reversible blue-shift interpreted with a basic model as an aggregate morphological change. In parallel to these INPS experiments other techniques will be necessary to well understand the water interaction on this type of soot which is known to be highly hydrophilic. We intend also to measure in the near future by environmental transmission electron microscopy (ETEM) the evolution of the morphology and the microstructure of aircraft soot particles during water adsorption.

\section{EXPERIMENTAL METHODS}

Gold nanodisks are fabricated by EBL (electron beam lithography), they are deposited onto a borosilicate glass window via a "lift-off process". The glass window presents a nanostructured surface of $720 \times 720 \mu \mathrm{m}^{2}$ with gold nanodisks having a center-to-center distance $<\mathrm{d}_{\mathrm{c}-\mathrm{c}}>=297.9 \pm$ $1.2 \mathrm{~nm}$, an average height of $<\mathrm{h}>=24.4 \pm 0.1 \mathrm{~nm}$, and an in-plane diameter of $\sim 100 \mathrm{~nm}$ (the inplane absolute uncertainty is not accurate by AFM measurements). The EBL technique allows a precise control of the shape, the size and the distance between the gold nanodisks (figure S4). 
Lastly, we have deposited on gold nanodisks by RF magnetron sputtering a $\mathrm{SiO}_{2}$ layer of about 10 nm.

To measure the LSPR response we used an experimental device wherein the sample holder (glass borosilicate window) fits into an UHV reactor consisting of an UHV stainless steel cube (CF DN 40) with two glass windows. The sample is illuminated by an optical fiber (Avantes, IR200-FC-2) connected to a tungsten halogen source (Avantes, AvaLight-HAL-S). The fiber is mounted on a collimating lens (Avantes, COL-UV/VIS ) allowing the sample to have a coherent beam of parallel light. The signal transmitted by the sample is collected by a second fiber mounted on the second collimator lens (Avantes, COL-UV/VIS). It is collected and analyzed in the $360-900 \mathrm{~nm}$ spectral range by a UV-VIS spectrometer (CCD detector, Avantes Avaspec-ULS3648 USB2) which is monitored by the Avantes "Avasoft-Full” software.

\section{COMPUTATIONAL METHOD}

In order to model our result, we have briefly studied the propagation of electromagnetic waves in a stratified medium that contains dielectric and absorbing elements. We have developed a general numerical model for computation reflectance, transmittance and absorbance of multilayer thin film systems, based on the analytical equations given by Born and $\mathrm{Wolf}^{33}$. The value of the layer system reflection and transmission coefficients follows the Fresnel's equations for transverse-electric polarized light. We have supposed that the multilayer thin film system is situated between two infinite dielectric media. Indeed, for the multilayer system there are several ways to obtain an expression for radiative properties such as reflectance and transmittance. We here have used the transfer matrix method that can be easily extended to multilayers, to investigate the optical characteristics with each layer thickness lower than the wavelength of the incident light.

The proposed multilayers consists in a succession of homogenous layers noted by subscripts 1,2 , and 3 so that: layer 1 is soot, layer 2 is silicon dioxide, and layer 3 is made of gold on a transparent glass substrate (layer 4). The layer thickness and the complex refractive index of the $j$-th layer $(j=1$, 
2, 3) is given by $h_{j}$ and $\tilde{n}_{j}=n_{j}+i k_{j}$, respectively. $n_{j}$ and $k_{j}$ represent the real part of the refractive index and the extinction coefficient of the $j$ medium forming the thin-film system. The refractive index of $\mathrm{SiO}_{2}\left(n_{2}\right)$ and glass substrate $\left(n_{4}\right)$ are not complex and $n_{2}=1.471$ and $n_{4}=1.514$ constant values were considered. ${ }^{34}$

In this work, the transfer matrix method ${ }^{33}$ is used in our simulation, so that the interference matrix of the $j$-th layer can be expressed by:

$$
\mathbf{M}_{\mathbf{j}}=\left[\begin{array}{cc}
\cos \beta_{j} & -\frac{i}{p_{j}} \sin \beta_{j} \\
-i p_{j} \sin \beta_{j} & \cos \beta_{j}
\end{array}\right]
$$

where, $\beta_{j}$ and $p_{j}$ are defined as $(2 \pi / \lambda) n_{j} h_{j} \cos \left(\theta_{j}\right)$ and $n_{j} \cos \left(\theta_{j}\right)$, respectively. $\theta_{0}$ denotes the incident angle in air (refractive index $\mathrm{n}=1$ ) and the complex angles are determined by Snell's law: $\sin \left(\theta_{0}\right)=$ $\tilde{n}_{j} \sin \left(\theta_{j}\right), j=1,2,3$. Finally, the multilayers system matrix $\mathbf{M}$ is given by:

$$
\mathbf{M}=\mathbf{M}_{1} \mathbf{M}_{2} \mathbf{M}_{3}
$$

This method is well suitable when dealing with multilayers. From the preceding matrix, we obtain the reflection and transmittance coefficients $r$ and $t$ through the films, denoted as Fresnel's equation in the matrix representation as follows:

$$
\begin{aligned}
& r=\frac{\left[\mathbf{M}(\mathbf{1}, \mathbf{1})+\mathbf{M}(\mathbf{1}, \mathbf{2}) p_{4}\right] p_{0}-\left[\mathbf{M}(\mathbf{2 , 1})+\mathbf{M}(2,2) p_{4}\right]}{\left[\mathbf{M}(\mathbf{1}, \mathbf{1})+\mathbf{M}(\mathbf{1}, \mathbf{2}) p_{4}\right] p_{0}+\left[\mathbf{M}(\mathbf{2 , 1})+\mathbf{M}(2,2) p_{4}\right]} \\
& t=\frac{2 p_{0}}{\left[\mathbf{M}(\mathbf{1}, \mathbf{1})+\mathbf{M}(\mathbf{1}, \mathbf{2}) p_{4}\right] p_{0}+\left[\mathbf{M}(\mathbf{2 , 1})+\mathbf{M}(\mathbf{2}, \mathbf{2}) p_{4}\right]}
\end{aligned}
$$

where $p_{0}=n_{0}=1$. For our simulation we have used the normal incidence $\theta_{0}=0$. 
Then, the total reflectance $R$ and transmittance $T$ can be obtained as:

$$
\begin{aligned}
& R=|r|^{2} \\
& T=\frac{p_{4}}{p_{0}}|t|^{2}
\end{aligned}
$$

and the wavelength dependence of the refractive index and the extinction coefficient for gold thin film are given by Gao et al. ${ }^{35}$ Then, we can get the value of absorbance calculated for different thickness $(h)$ and refractive index $(n)$ of the soot layer.

\section{ACKNOWLEDGMENTS}

The soot samples we used in this work are precisely described in doi:10.1007/s10874-006-9043-9. BD cordially thanks Prof. H. Dallaporta (Aix-Marseille University) for fruitful discussions. Nanofabrication processes were performed in PLANETE cleanroom facility (CINaM, Marseille).

\section{SUPPORTING INFORMATION}

Supporting information available: Table S1, Figures S1 to S4, calculation of the EM field evanescent decay length. 


\section{REFERENCES}

(1) Kalyuzhny, G.; Schneeweiss, M. A.; Shanzer, A.; Vaskevich, A.; Rubinstein, I. Differential plasmon spectroscopy as a tool for monitoring molecular binding to ultrathin gold films. J. Am. Chem. Soc. 2001, 123, 3177-3178.

(2) Malinsky, M.; Kelly, K.; Schatz, G.; Van Duyne, R. P. Chain length dependence and sensing capabilities of the localized surface plasmon resonance of silver nanoparticles chemically modified with alkanethiol self-assembled monolayers. J. Am. Chem. Soc. 2001, 123, 1471-1482.

(3) Connolly, S.; Cobbe, S.; Fitzmaurice, D. Effects of Ligand-Receptor Geometry and Stoichiometry on Protein-Induced Aggregation of Biotin-Modified Colloidal Gold. J. Phys. Chem. B 2001, 105, 2222-2226.

(4) Haynes, C. L.; Van Duyne, R. P. Nanosphere lithography: a versatile nanofabrication tool for studies of size-dependent nanoparticle optics. J. Phys. Chem. B 2001, 105, 5599-5611.

(5) Riboh, J. C.; Haes, A. J.; McFarland, A. D.; Yonzon, C. R.; Van Duyne, R. P. A nanoscale optical biosensor: real-time immunoassay in physiological buffer enabled by improved nanoparticle adhesion. J. Phys. Chem. B 2003, 107, 1772-1780.

(6) Jung, L. S.; Campbell, C. T.; Chinowsky, T. M.; Mar, M. N.; Yee, S.S. Quantitative interpretation of the response of surface plasmon resonance sensors to adsorbed films. Langmuir 1998, 14, 5636-5648.

(7) Stuart, D.; Haes, A.; Yonzon, C.; Hicks, E.; Van Duyne, R. P. Biological applications of localized surface plasmonic phenomenae. IEE Proc.-Nanobiotechnol. 2005, 152, 13-32.

(8) Barbillon, G.; Bijeon, J.-L.; Bouillard, J.-S.; Plain, J.; Lamy de la Chapelle, M.; Adam, P.-M.; Royer, P. Detection in near-field domain of biomolecules adsorbed on a single metallic nanoparticle. J. Microsc.-Oxf. 2008, 229, 270-274.

(9) Chen, S.; Svedendahl, M.; Käll, M.; Gunnarsson, L.; Dmitriev, A. Ultrahigh sensitivity made simple: nanoplasmonic label-free biosensing with an extremely low limit-of-detection for bacterial and cancer diagnostics. Nanotechnology 2009, 20, 434015. 
(10) Larsson, E. M.; Langhammer, C.; Zoric, I.; Kasemo, B. Nanoplasmonic probes of catalytic reactions. Science 2009, 326, 1091-1094.

(11) Barbillon, G. Theoretical and experimental study of localized surface plasmon resonance biochemical nanosensors on metallic nanoparticles, Ph.D. thesis, Univ. of Troyes, France, 2007.

(12) Kärcher, B.; Yu, F. Role of aircraft soot emissions in contrail formation. Geophys. Res. Lett. 2009, 36, L01804.

(13) Ramanathan, V.; Carmichael, G. Global and regional climate changes due to black carbon. Nature Geoscience 2008, 1, 221-227.

(14) Alcala-Jornod, C.; Van den Bergh, H.; Rossi, M. J. Can soot particles emitted by airplane exhaust contribute to the formation of aviation contrails and cirrus clouds ? Geophys. Res. Lett. 2002, 29, 1820.

(15) Jacobson, M. Z. Strong radiative heating due to the mixing state of black carbon in atmospheric aerosols. Nature 2001, 409, 695-697.

(16) Bond, T. C.; Doherty, S. J.; Fahey, D. W.; Forster, P. M.; Berntsen, T.; De Angelo, B. J.; Flanner, M. G.; Ghan, S.; Kärcher, B.; Koch, D. Bounding the role of black carbon in the climate system: a scientific assessment. J. Geophys. Res. 2013, 118, 5380-5552.

(17) Kahnert, M. Modelling the optical and radiative properties of freshly emitted light absorbing carbon within an atmospheric chemical transport model. Atmos. Chem. Phys. 2010, 10, 14031416.

(18) Liu, L.; Mishchenko, M. I. Effects of aggregation on scattering and radiative properties of soot aerosols. J Geophys. Res. 2005, 110, D11211.

(19) Carrico, C. M.; Petters, M. D.; Kreidenweis, S. M.; Sullivan, A. P.; McMeeking, G. R.; Levin, E. J. T.; Engling, G.; Malm, W. C.; Collett Jr., J. L. Water uptake and chemical composition of fresh aerosols generated in open burning of biomass. Atmos. Chem. Phys. 2010, 10, 5165-5178. 
(20) Cheng, T.; Gu, X.; Yu, W.; Hao, C. Effects of atmospheric water on the optical properties of soot aerosols with different mixing states. Journal of Quantitative Spectroscopy and Radiative Transfer 2014, 147, 196-206.

(21) Mikhailov, E. F.; Vlasenko, S. S.; Podgorny, I. A.; Ramanathan, V.; Corrigan, C. E. Optical properties of soot-water drop agglomerates: an experimental study. J Geophys. Res. 2006, 111, D07209.

(22) Arima, K.; Xingyi Deng, P. J., Bluhm, H.; Salmeron, M. Water Adsorption solvation, and deliquescence of potassium bromide thin films on $\mathrm{SiO}_{2}$ studied by ambient-pressure x-ray photoelectron spectroscopy. J. Phys. Chem. C 2010, 114, 14900-14906.

(23) Demirdjian, B.; Ferry, D.; Suzanne, J.; Popovicheva, O. B.; Persiantseva, N. M.; Shonija, N. K. Heterogeneities in the microstructure and composition of aircraft engine combustor soot: impact on the water uptake. Journal of Atmospheric Chemistry 2007, 56, 83-103.

(24) Maugendre, M.; Yon, J.; Coppalle, A.; Ouf, F. X. Measurement of the optical properties of soot particles. Application of the optical index determination taking into account their agglomerate structure; Proceedings of the 5th european thermal-sciences conference; Editors: G. G. M. Stoffels, T. H. van der Meer and A. A. van Steenhoven; ISBN 978-90-386-1274-4; Eindhoven, N.L., 2008.

(25) Van-Hulle, P. Characterisation of aerosols emitted by the combustion of hydrocarbons: application to the measurement of the soot refractive index, Ph.D. thesis, Univ. of Rouen, France, 2002.

(26) Ganhua, F.; Weiping, C.; Yanjie, G.; Jinglian, H. A new optical absorption peak for Au/SiO2 nanocomposite formed by sonochemistry. J. Phys. Condens. Matter 2003, 15, L285-L289.

(27) Hartland, G. V. Coherent excitation of vibrational modes in metallic nanoparticles. Annu. Rev. Phys. Chem. 2006, 57:403-30.

(28) Ung, T.; Liz-Marzán, L. M.; Mulvaney, P. Optical properties of thin films of Au@SiO2 particles. J. Phys. Chem. B 2001, 105, 3441-3452. 
(29) Wang, L.-D.; Zhang, T.; Zhu, S.-Q.; Zhang, X.-Y.; Wang, Q.-L.; Liu, X.; Li, R.-Z. Twodimensional ultrathin gold film composed of steadily linked dense nanoparticle with surface plasmon resonance. Nanoscale Research Letters 2012, 7, 683.

(30) Popovicheva, O. B.; Persiantseva, N. M.; Kireeva, E. D.; Khokhlova, T. D.; Shonija, N. K. Quantification of the hygroscopic effect of soot aging in the atmosphere: laboratory simulations. J. Phys. Chem. A 2011, 115, 298-306.

(31) Zhang, R.; Khalizov, A. F.; Pagels, J.; Zhang, D.; Xue, H.; McMurry, P. H. Variability in morphology, hygroscopicity, and optical properties of soot aerosols during atmospheric processing. PNAS 2008, 105, 10291-10296.

(32) Gross, S.; Esselborn, M.; Weinzierl, B.; Wirth, M.; Fix, A.; Petzold, A. Aerosol classification by airborne high spectral resolution lidar observations. Atmospheric Chemistry and Physics 2013, 13, 2487-2505.

(33) Born, M.; Wolf, E. Principles of Optics, 7th Edition; Cambridge University Press: Cambridge, U.K., 1999.

(34) Gao, L.; Lemarchand, F.; Lequime, M. Refractive index determination of $\mathrm{SiO}_{2}$ layer in the UV/Vis/NIR range: spectrophotometric reverse engineering on single and bi-layer designs. $J$. Europ. Opt. Soc. Rap. Public. 2013, 8, 13010.

(35) Gao, L.; Lemarchand, F.; Lequime, M. Comparison of different dispersion models for single layer optical thin film index determination. Thin Solid Films 2011, 520, 501-509. 